Note

\title{
A new potato variety, "Haruka", improved for culinary quality and disease resistance
}

\author{
Akira Kobayashi*1), Nobuhiro Mukoujima ${ }^{1)}$, Shogo Tsuda ${ }^{1}$, Motoyuki Mori' ${ }^{1}$, Akiko Ohara-Takada ${ }^{1,2}$ \\ and Norikazu Takada ${ }^{1,3}$ \\ 1) National Agricultural Research Center for Hokkaido Region, Shinsei, Memuro, Kasai-gun, Hokkaido 082-0071, Japan \\ 2) Present Address: National Institute of Crop Science, 2-21-18 Kannondai, Tsukuba, Ibaraki 305-8518, Japan \\ 3) Present Address: National Center for Seeds and Seedlings, 2-2 Fujimoto, Tsukuba, Ibaraki 305-0852, Japan
}

\begin{abstract}
Haruka is a new table-stock potato variety with parti-colored red/white-skinned tubers, white flesh, medium maturing and good culinary quality. It was selected from a cross between T9020-8 as the female parent and Sayaka as the male parent, and was released in 2007. Agronomic characters of the Haruka were checked from 2003 to 2007. Its marketable yield is $103 \%$ of the Sayaka and $124 \%$ of the Irish Cobbler. The average size of a tuber was $104 \mathrm{~g}$. The starch value of Haruka was $16.2 \%$. Dormancy period of the tuber was 105 days. In comprehensive evaluations of product quality, Haruka tubers shows a little disintegration of the flesh after boiling, the texture was rated as pasty, and the boiled tuber had favorable taste. Haruka was superior or equally good to Irish Cobbler and Sayaka for salad quality and had a high processing ability for chilled potato, whereas it was not suitable for chips and french-fry. Haruka is resistant to the golden nematode, and good resistant to brown rot and tuber rot, while it is susceptible to potato virus $\mathrm{Y}$, common scab and foliage late blight.
\end{abstract}

Key Words: potato, variety, Haruka, table stock.

In recent Japan, the use of potato for home cooking has gradually decreased (Statistics Bureau 2008). On the other hand, the demand for prepared meals with potato, such as potato salad, croquettes and pouch-packed food, has gradually increased due to a shift in the Japanese lifestyle. Irish Cobbler (Japanese name "Danshakuimo") (Clark and Lombard 1951) is the leading table-stock potato variety in Japan (Mori et al. 2007), which is sold not only in the fresh market but also in the form of processed food for salads and croquettes. The tuber of Irish Cobbler has deep eyes that result in a low efficiency of peeling of the tuber skin, and shows notable enzymatic browning in freshly cut tuber slices, in addition to postcooking discoloration (Kobayashi et al. 2002). The tubers also have a low tolerance to mechanical damage and are frequently bruised (Takada et al. 2000). Thus, the major variety Irish Cobbler has some defects in raw materials as well as expenses required for manual trimming of the bruised sections. The potato-production areas have been increasingly infested with golden nematode every year in Hokkaido, Japan. Irish Cobbler is susceptible to the pathotype Ro1 of the golden nematode (Globodera rostochiensis) (Kushida and Momota 2005). Therefore, further breeding efforts are required to develop a table-stock variety that has a high processing ability and a golden nematode resistance.

Communicated by M. Iwanaga

Received March 26, 2009. Accepted May 14, 2009.

*Corresponding author (e-mail: kobajr@naro.affrc.go.jp)
Here, we describe the development of a new potato variety having both good culinary quality and the golden nematode resistance.

\section{Breeding process}

The new variety Haruka was initially termed as T9450-1, renamed as Kachikei 7, and then finally as Hokkai 94. This clone was selected from the progeny of a cross between T9020-8, as the female parent, and Sayaka, as the male parent. A complete pedigree is shown in Figure 1. T9020-8 is a white-fleshed, particolored red/light yellow-skinned, high yield, middle-late maturing variety. Sayaka is a whitefleshed, white-skinned, middle maturing variety used for salads. In 1998, 1763 seedlings were grown in a greenhouse and 1638 seedling tubers were harvested. In the next year, 1617 seedling tubers were used for second clonal seedling selection in a field at Memuro in Hokkaido on the basis of their general agricultural traits. In 2000, 8-hill selection was conducted, followed by a 1-year preliminary yield trial and a 5 -year yield trial. The selected clonal line was designated as Kachikei 7 in 2002, and as Hokkai 94 in 2003. Local adaptability was evaluated at the three different locations, the Hokkaido Central Agricultural Experiment Station in 2003, the Iwate Agricultural Research Center and the Kagoshima Prefecture Agricultural Experiment Station in 2004-2006. Performance tests the recommended varieties were conducted at the Hokkaido Central Agricultural Experiment Station and the Hokkaido Prefectural Tokachi, Kitami, and 


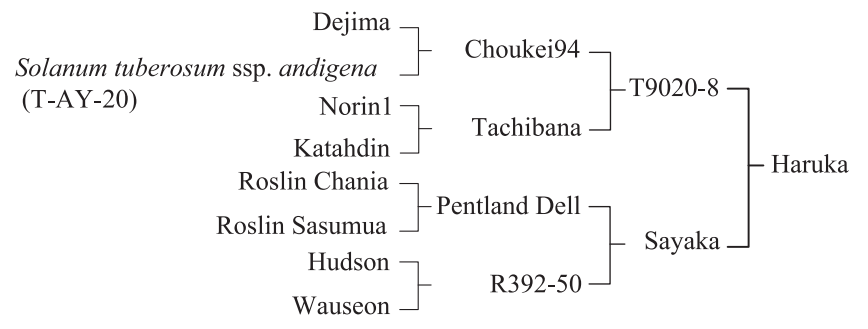

Fig. 1. Pedigree of Haruka
Kamikawa Agricultural Experiment Stations in 2004-2006, and further at 9 farm sites in Hokkaido in 2005-2006. Hokkai 94 was released as Haruka in 2007, and officially registered by the Ministry of Agriculture, Forestry and Fisheries of Japan in 2009.

Agronomic characteristics

From 2003-2007, agronomic traits of Haruka, Sayaka and Irish Cobbler were examined. Seed tubers of each variety were hand-cut into pieces and planted in the field at

Table 1. Analysis of variance for several parameters among three potato varieties over five year trials

\begin{tabular}{|c|c|c|c|c|c|}
\hline$\overline{\text { Parameter }}$ & sources & d.f. & Sum of square & Mean square & $F$-value \\
\hline \multirow[t]{5}{*}{ Total yield } & Year & 4 & 15663413 & 3915853.222 & $22.2277 * * *$ \\
\hline & Variety & 2 & 2190398 & 1095198.822 & $6.2167 * *$ \\
\hline & Year $\times$ variety & 8 & 1570476 & 196309.4889 & 1.1143 \\
\hline & Error & 30 & 5285088 & 176169.6 & \\
\hline & Total & 44 & 24709374 & & \\
\hline \multirow[t]{5}{*}{ Marketable yield } & Year & 4 & 13638726 & 3409681 & $20.2578 * * *$ \\
\hline & Variety & 2 & 4705696 & 2352848 & $13.9789 * * *$ \\
\hline & Year $\times$ variety & 8 & 1301858 & 162732.3 & 0.9667 \\
\hline & Error & 30 & 5049419 & 168314 & \\
\hline & Total & 44 & 24695699 & & \\
\hline \multirow[t]{5}{*}{ Starch value } & Year & 4 & 20.53467 & 5.133667 & $12.827 * * *$ \\
\hline & Variety & 2 & 2.896444 & 1.448222 & $3.6186^{*}$ \\
\hline & Year $\times$ variety & 8 & 17.40133 & 2.175167 & $5.4349 * * *$ \\
\hline & Error & 30 & 12.00667 & 0.400222 & \\
\hline & Total & 44 & 52.83911 & & \\
\hline \multirow[t]{5}{*}{ Days to emergence from planting } & Year & 4 & 926.3556 & 231.5889 & $289.4861 * * *$ \\
\hline & Variety & 2 & 98.71111 & 49.35556 & $61.6944 * * *$ \\
\hline & Year $\times$ variety & 8 & 38.17778 & 4.772222 & $5.9653 * * *$ \\
\hline & Error & 30 & 24 & 0.8 & \\
\hline & Total & 44 & 1087.244 & & \\
\hline \multirow[t]{5}{*}{ Maturity } & Year & 4 & 580.8 & 145.2 & $7.2199 * * *$ \\
\hline & Variety & 2 & 2937.778 & 1468.889 & $73.0387 * * *$ \\
\hline & Year $\times$ variety & 8 & 33.33333 & 4.166667 & 0.2072 \\
\hline & Error & 30 & 603.3333 & 20.11111 & \\
\hline & Total & 44 & 4155.244 & & \\
\hline \multirow[t]{4}{*}{ Dormancy period } & Year & 4 & 671.6 & 167.9 & 2.322 \\
\hline & Variety & 2 & 644.933 & 322.467 & $4.460^{*}$ \\
\hline & Error & 8 & 578.4 & 72.3 & \\
\hline & Total & 14 & 1894.933 & & \\
\hline \multirow[t]{5}{*}{ Haulm length } & Year & 4 & 600.3076 & 150.0769 & $9.6638^{* * *}$ \\
\hline & Variety & 2 & 3506.012 & 1753.006 & $112.8803^{* * *}$ \\
\hline & Year $\times$ variety & 8 & 185.8898 & 23.23622 & 1.4962 \\
\hline & Error & 30 & 465.8933 & 15.52978 & \\
\hline & Total & 44 & 4758.103 & & \\
\hline \multirow[t]{5}{*}{ No. of main stems per hill } & Year & 4 & 4.048 & 1.012 & 2.6851 \\
\hline & Variety & 2 & 25.49511 & 12.74756 & $33.8231 * * *$ \\
\hline & Year $\times$ variety & 8 & 4.576 & 0.572 & 1.5177 \\
\hline & Error & 30 & 11.30667 & 0.376889 & \\
\hline & Total & 44 & 45.42578 & & \\
\hline \multirow[t]{5}{*}{ No.of tubers per hill } & Year & 4 & 59.74889 & 14.93722 & $16.7667 * * *$ \\
\hline & Variety & 2 & 21.38533 & 10.69267 & $12.0022 * * *$ \\
\hline & Year $\times$ variety & 8 & 13.01911 & 1.627389 & 1.8267 \\
\hline & Error & 30 & 26.72667 & 0.890889 & \\
\hline & Total & 44 & 120.88 & & \\
\hline
\end{tabular}

$*, * *, * * *$ Significant at the $5 \%, 1 \%$ and $0.1 \%$ levels, respectively. 
Memuro. Plot size was three rows, each $4.2 \mathrm{~m}$ long with $79 \mathrm{~cm}$ between rows and a $30 \mathrm{~cm}$ spacing between potatoes within rows. Plots replicated three times. The center of one row was used for measurements. Analysis of variance (ANOVA) for the total yield, marketable yield, starch value, days to emergence from planting, maturity, dormancy period, haulm length, number of main stems per hill, and number of tubers per hill were performed (Table 1). Significant differences among the varieties were observed in terms of the dormancy period and number of main stems per hill. The total yields, marketable yields, maturity, haulm lengths, and number of tubers per hill were significantly different among the varieties and in different years. In addition to significant differences among the varieties and years, there were significant year by variety interactions on starch values and days to emergence from planting.

In the field conditions, the Haruka plants emerged at almost the same time as the Sayaka plants and slightly later than the Irish Cobbler plants (Table 2 and Table 3). In Haruka, the maturity was classified as "medium" in
Hokkaido, and the senescence took place a few days to 1 week later than in Sayaka and 17 to 21 days later than in Irish Cobbler. The haulm length was almost the same as that of Sayaka, and $20 \mathrm{~cm}$ longer than that of Irish Cobbler (Table 2). Although Haruka exhibited fewer main stems per hill than Irish Cobbler, the number of tubers was almost the same in these 2 varieties. In Haruka, the growth habit was semi-erect, and the stem color was red-violet. The leaves were green and the flowers were red-purple. In spite of a large number of flowers observed in the field, open-pollinated berries were seldom produced in the field condition. The tuber shape was oval, and the flesh color was white (Fig. 2). Haruka had particolored red/white skin tubers, that is, the skin color around the eyes was red and the remainder was white. The tuber eyes were shallow.

The total yield of Haruka was $103 \%$ of that of Sayaka and $114 \%$ of that of Irish Cobbler (Table 3 ). Its marketable yield was $103 \%$ of that of Sayaka and $124 \%$ of that of Irish Cobbler. The average size of a tuber was $104 \mathrm{~g}$, which was similar to that of Sayaka (109g), and bigger than that of Irish

Table 2. Agronomic characteristics of Haruka and control varieties (Means of 2003-2007)

\begin{tabular}{lccccc}
\hline \hline Variety & Emergence date & Senescence date & Haulm length $(\mathrm{cm})$ & No. of main stems per hill & No. of tubers per hill \\
\hline Haruka & $5.29 \mathrm{a}^{a}$ & $9.11 \mathrm{a}^{a}$ & $59.8 \mathrm{a}^{a}$ & $2.7 \mathrm{a}^{a}$ & $9.2 \mathrm{ab}^{a}$ \\
Sayaka & $5.30 \mathrm{a}$ & $9.6 \mathrm{~b}$ & $56.2 \mathrm{a}$ & $2.9 \mathrm{a}$ & $8.4 \mathrm{a}$ \\
Irrish Cobbler & $5.26 \mathrm{~b}$ & $8.24 \mathrm{c}$ & $39.6 \mathrm{~b}$ & $4.4 \mathrm{~b}$ & $10.1 \mathrm{~b}$ \\
\hline
\end{tabular}

The planting dates were April 28, 2003, April 27, 2004, April 27, 2005, May 8, 2006 and May 9, 2007.

${ }^{a}$ Values within a column followed by different letters are significantly differnt according to Tukey's test $(\mathrm{P}=0.05)$.

Table 3. Comparative performance of Haruka and control varieties

\begin{tabular}{|c|c|c|c|c|c|c|c|}
\hline \multirow{2}{*}{ Parameter } & \multirow{2}{*}{ Variety } & \multicolumn{5}{|c|}{ Year } & \multirow{2}{*}{ Means } \\
\hline & & 2003 & 2004 & 2005 & 2006 & 2007 & \\
\hline \multirow[t]{3}{*}{ Total yield $^{b}(\mathrm{~kg} / 10 \mathrm{a})$} & Haruka & 4,330 & 4,251 & 4,991 & 4,009 & 3,435 & $4,203 \mathrm{a}^{a}$ \\
\hline & Sayaka & 4,399 & 4,669 & 5,009 & 3,497 & 2,852 & $4,085 \mathrm{a}$ \\
\hline & Irish Cobbler & 3,617 & 4,208 & 4,290 & 3,414 & 2,908 & $3,687 \mathrm{~b}$ \\
\hline \multirow[t]{3}{*}{ Marketable yield ${ }^{c}(\mathrm{~kg} / 10 \mathrm{a})$} & Haruka & 3,891 & 3,786 & 4,517 & 3,613 & 3,105 & $3,782 \mathrm{a}$ \\
\hline & Sayaka & 4,122 & 4,118 & 4,447 & 3,214 & 2,541 & $3,688 \mathrm{a}$ \\
\hline & Irish Cobbler & 3,231 & 3,543 & 3,513 & 2,901 & 2,082 & $3,054 \mathrm{~b}$ \\
\hline \multirow[t]{3}{*}{ Starch value } & Haruka & 18.4 & 14.9 & 15.0 & 15.4 & 17.3 & $16.2 \mathrm{a}$ \\
\hline & Sayaka & 17.2 & 16.8 & 15.6 & 17.7 & 16.8 & $16.8 \mathrm{a}$ \\
\hline & Irish Cobbler & 16.7 & 16.3 & 15.8 & 16.9 & 16.5 & $16.4 \mathrm{a}$ \\
\hline \multirow[t]{3}{*}{ Days to emegence from planting } & Haruka & 27 & 31 & 33 & 20 & 25 & $27 \mathrm{a}$ \\
\hline & Sayaka & 29 & 30 & 35 & 19 & 26 & $28 \mathrm{a}$ \\
\hline & Irish Cobbler & 25 & 25 & 30 & 18 & 23 & $24 \mathrm{~b}$ \\
\hline \multirow[t]{3}{*}{ Maturity $^{d}$ (days to senescence) } & Haruka & 135 & 134 & 137 & 127 & 128 & $132 \mathrm{a}$ \\
\hline & Sayaka & 130 & 128 & 132 & 126 & 120 & $127 \mathrm{~b}$ \\
\hline & Irish Cobbler & 114 & 117 & 119 & 110 & 109 & $114 \mathrm{c}$ \\
\hline \multirow[t]{3}{*}{ Dormancy period $^{e}$ (days to sprout) } & Haruka & 105 & 101 & 115 & 102 & 104 & $105 \mathrm{a}$ \\
\hline & Sayaka & 117 & 121 & 130 & 117 & 110 & $119 \mathrm{a}$ \\
\hline & Irish Cobbler & 96 & 87 & 121 & 100 & 120 & $105 \mathrm{a}$ \\
\hline
\end{tabular}

${ }^{a}$ Values within a column followed by different letters are significantly differnt according to Tukey's test $(\mathrm{P}=0.05)$.

${ }^{b}$ Yield data recorded from a single-row plot $4.8 \mathrm{~m}$ long with $30 \mathrm{~cm}$ plant spacing and 3 replications. Average of 3 sites each year. Total yield includes tubers above $20 \mathrm{~g}$.

${ }^{c}$ Marketable yield includes tubers above $60 \mathrm{~g}$.

${ }^{d}$ Maturity in days from planting until plant senescence $(125=$ midium-early maturing).

${ }^{e}$ Tubers were stored at $18^{\circ} \mathrm{C}$ in the dark after harvest. Domancy period indicates days from plant senescence to a $5 \mathrm{~mm}$ sprout. 


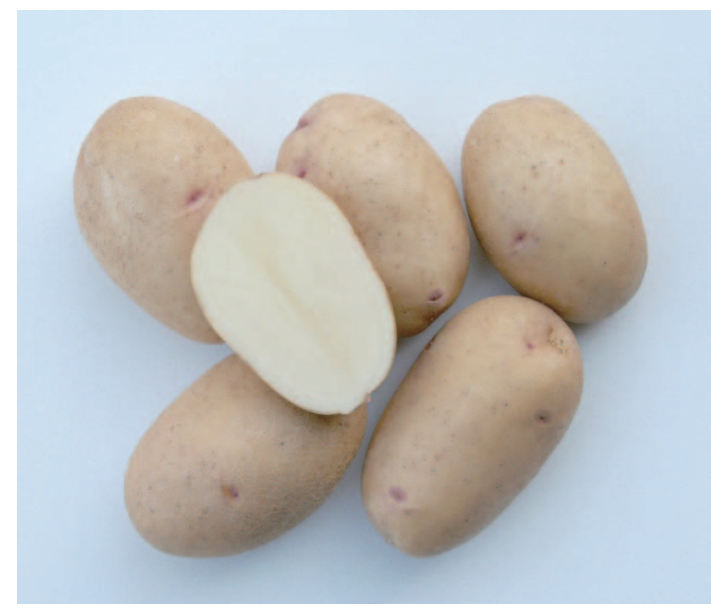

Fig. 2. Tubers of Haruka

Cobbler $(83 \mathrm{~g})$. The size distribution of the tubers was as follows: $1 \%$, less than $20 \mathrm{~g} ; 8 \%, 20-59 \mathrm{~g} ; 41 \%, 60-119 \mathrm{~g} ; 39 \%$, $120-189 \mathrm{~g}$; and $11 \%$, greater than $190 \mathrm{~g}$. In terms of physiological traits in the tubers, Haruka demonstrated a good resistance to internal necrosis and tuber crack similar to that observed in Sayaka. Haruka was slightly more susceptible to second growth than Sayaka, but the susceptibility was similar to that shown by Irish Cobbler. Haruka exhibited a better response to hollow hearts than did Irish Cobbler. The starch value of Haruka was $16.2 \%$, which was similar to those of Irish Cobbler (16.4\%) and Sayaka (16.8\%). The dormancy period was 105 days, which was similar to those of Sayaka (119 days) and Irish Cobbler (105 days). The tolerance level of the tubers to mechanical damage was high; nearly the same as that of the Sayaka tubers, but higher than that of the Irish Cobbler tubers showing a low tolerance level. Glycoalkaloid content in the tubers was measured as described by Carman et al. (1986). The total glycoalkaloid content in the tubers of Haruka was $5.9 \mathrm{mg}$ per $100 \mathrm{~g}$ fresh weight, and those of the Irish Cobbler and Sayaka tubers were $5.1 \mathrm{mg}$ and $4.9 \mathrm{mg}$ per $100 \mathrm{~g}$ fresh weight, respectively.

Sensory evaluations of boiled potatoes revealed that the Haruka tubers were almost free from postpeeling enzymatic browning, compared with the Irish Cobbler and Sayaka tubers (Table 4). The Haruka tubers also showed slightly less postcooking discoloration than the Irish Cobbler tubers, and slightly more discoloration than the Sayaka tubers. After boiling, the Haruka tubers slough slightly; however, the sloughing was tended to less than the Irish Cobbler and Sayaka tubers. Boiled tubers of Haruka had a slightly more favorable taste than those of the Irish Cobbler and Sayaka tubers. An evaluation of the utility of Haruka for salad processing was conducted in 2003-2006 by Q.P. Corporation (Tokyo, Japan). The color of the salad was white. The texture was rated as smooth, same as that of Sayaka, while that of Irish Cobbler was rated as mealy. The flavor was good, similar to those in Irish Cobbler and Sayaka. Haruka was rated as superior or equally good to Irish Cobbler and Sayaka for application to commercial salad production. Processing evaluation for chilled potato was carried out by vacuum packing of the peeled and heated tubers, which was conducted by Shin-Shin Foods Co., Ltd. (Tokyo, Japan). The yield rate of chilled potato in Haruka was $75.9 \%$, which was higher than those in Sayaka (71.2\%) and Irish Cobbler $(68.3 \%)$. Therefore, it was found that Haruka had a high processing ability for chilled potato processing. Haruka was not suitable for chips and french-fry, similar to Sayaka and Irish Cobbler, because chip color and french-fry color of Haruka were darker than that of the chipping variety Toyoshiro and french-fry processing variety Hokkaikogane.

\section{Disease evaluations}

Susceptibility tests for brown rot (Ralstonia solanacearum) were conducted at Aino, Nagasaki using naturally occurring inocula in 2003-2006. Many of varieties currently cultivated in Japan, including Irish Cobbler and Sayaka, are susceptible to brown rot, however, Haruka exhibited good resistance to brown rot. Haruka was resistant to the pathotype Ro1 of the golden nematode. Haruka was susceptible to both the common strains of potato virus $\mathrm{Y}$ $\left(\mathrm{PVY}^{\mathrm{O}}\right)$ and PVY-T (Japanese isolate of PVYN), common scab (Streptomyces turgidiscabies and S. scabies) and foliage late blight (Phytophtora infestans), similar to Irish Cobbler and Sayaka. Susceptibility tests for tuber rot were

Table 4. Sensory evaluation of Haruka and control varieties (Means of 2003-2007)

\begin{tabular}{|c|c|c|c|c|c|}
\hline \multirow{2}{*}{ Variety } & \multirow{2}{*}{ Peeled color $^{a}$} & \multicolumn{4}{|c|}{ Boiling } \\
\hline & & Boiled color $^{b}$ & Sloughing $^{c}$ & Mealiness $^{d}$ & Taste $^{e}$ \\
\hline Haruka & $2.0 \mathrm{a}^{f}$ & $2.6 \mathrm{a}^{f}$ & $3.0 \mathrm{a}^{f}$ & $2.6 \mathrm{a}^{f}$ & $3.8 \mathrm{a}^{f}$ \\
\hline Sayaka & $2.7 \mathrm{ab}$ & $2.0 \mathrm{a}$ & $3.4 \mathrm{a}$ & $3.0 \mathrm{ab}$ & $3.2 \mathrm{a}$ \\
\hline Irish Cobbler & $5.0 \mathrm{~b}$ & $2.8 \mathrm{a}$ & $3.4 \mathrm{a}$ & $4.4 \mathrm{~b}$ & $3.4 \mathrm{a}$ \\
\hline
\end{tabular}

$\bar{a}$ The color of the peeled tuber was examined 1 hour after the skin was peeled and is based on a $1-5$ scale, with $1=$ no browning and $5=$ extensive browning.

${ }^{b}$ The color of a boiled tuber is based on a $1-5$ scale, with $1=$ no greying and $5=$ extensive greying.

$c$ Sloughing is based on a $1-6$ scale, with $1=$ no sloughing and $6=$ extensive sloughing.

${ }^{d}$ Mealiness is based on a 1 to 5 scale, with $1=$ not mealy and $5=$ very mealy.

$e$ Taste is based on a 1 to 5 scale, with $1=$ dislike and $5=$ like.

$f$ Values within a column followed by different letters are significantly differnt according to nonparametoric multiple comparison test $(\mathrm{P}=0.05)$. 
conducted at Hokkaido Prefectural Tokachi Agricultural Experiment Station under field conditions in 2003-2005. Tubers were planted in single rows with two replications. Each plot consisted of ten hills. Late blight susceptible variety Benimaru was planted as spreader row at intervals of two rows. Fungicide was applied only $2-4$ times throughout the season and frequent sprinkler-irrigation was applied to stimulate disease development. Haruka exhibited good resistance to tuber rot similar to that shown by Sayaka and greater than that shown by Irish Cobbler.

Haruka can be used not only for home cooking but also for commercial salad production. The first-class tubers can be provided to the fresh market, and second-class tubers can be used for salad processing. Furthermore, Haruka has golden cyst nematode resistance. Therefore, Haruka can be grown instead of Irish Cobbler in areas infested with the golden cyst nematode.

\section{Acknowledgments}

The authors thank the following support staff: Mr. N. Taira, Mr. A. Morizumi, Mr. T. Hirao, Mr. S. Nakamura, Mr. T. Takakura, Mr. K. Wada and Mr. H. Takahashi of the National Agricultural Research Center for Hokkaido Region.

\section{Literature Cited}

Carman, A.S. Jr., S.S.Kuan, G.M. Ware, O.J.Francis Jr. and G.P. Kirschenheuter (1986) Rapid high-performance liquid chromatographic determination of the potato glycoalkaloids. $\alpha$-solanine and $\alpha$-chaconine. J. Agric. Food Chem. 34: 279-282.

Clark, C.F. and P.M.Lombard (1951) Description of and key to American potato varieties. USDA Circular No. 741, Washington, DC.

Kobayashi,A., M.Mori, A.Takada, S.Tsuda, N.Takada, Y.Umemura, T.Nakao, T.Yoshida, T.Kimura and T.Maida (2002) Breeding of Yukirasha: Common Scab-Resistant Potato Variety for Table Stock. Breed. Sci. 52: 327-332.

Kushida,A. and Y.Momota (2005) Multiplication of Japanese populations of the potato cyst nematode, Globodera rostochiensis, on $\mathrm{H}_{1}$ resistant potato cultivar. J. Nematol. 35: 87-90.

Mori,M., S.Tsuda, N.Mukojima, A.Kobayashi, C.Matsuura-Endo, A.Ohara-Takada and I.S.M.Zaidul (2007) Breeding of potato cyst nematode resistant varieties in Japan. In: Haverkort, A.J. and B.V. Anisimov (eds.) Potato Production and Innovative Technologies. Wageningen Academic Publishers, pp. 328-339.

Statistics Bureau, Ministry of Internal Affairs and communications, Japan. (2008) Annual Report on the Family Income and Expenditure Survey (Income and Expenditure) 2007, Japan Statistical Association, p. 522.

Takada,A., A.Kobayashi, S.Tsuda and M.Mori (2000) Varietal differences of potato bruising. Report of the Hokkaido Branch, The Japanese Society of Breeding and Hokkaido Branch, The Crop Science Society of Japan 41: 77-78. 